\title{
OCUPAÇÃO VIRTUAL: DA FIAÇÃO DE PROPOSTAS À TRAMA ANTIRRACISTA
}

\author{
Greice Duarte de Brito Silva ${ }^{\mathrm{i}}$ \\ Graziela Ferreira de Melloi \\ Maria Helena Dantas dos Santos Nevesii
}

\begin{abstract}
Resumo: O presente texto apresenta a ocupação virtual desenvolvida por três fiandeiraspesquisadoras entre maio e setembro de 2020 na ação "Fiar com o FIAR iv na quarentena". A ocupação foi realizada na página do grupo de pesquisa no Facebook como alternativa para suscitar o diálogo com professores e outros interlocutores em tempos de suspensão provocada pela crise da COVID-19. Da proposta "Fiar com propostas de educação antirracista", destacase o papel da curadoria educativa e das narrativas autobiográficas como possibilidade de formação e ampliação de repertórios. Na direção de pedagogias vitais, a curadoria de conteúdo e forma inspirou outras estratégias interativas, ajudando a ressignificar afetos individuais e coletivos, tão importantes no caminho de engajamento contra o racismo.
\end{abstract}

Palavras-chave: Educação antirracista; Arte e pandemia; Curadoria virtual.

Resumem: En este trabajo se presenta la ocupación virtual desarrollada por tres investigadoresspinner hilanderas (que hacen trabajo de busqueda), entre mayo y septiembre de 2020, en la acción "Hilar com FIAR em la cuarentena", como una alternativa para incentivar el diálogo con docentes y diversos interlocutores en tiempos de suspensión, durante la crisis generada por COVID-19. Del propósito "Hilar con propuestas educativas antirracistas", se destaca el papel de la curaduría educativa y las narrativas (auto) biográficas como una posibilidad para la formación y expansión de repertorios. En la dirección de pedagogías vitales, la curaduría de contenido y forma inspiró otras estrategias interactivas, ayudando a resignificar los afectos individuales y colectivos, tan importantes en el camino del compromiso contra el racismo.

Palabras clave: Educación antirracista; Arte y pandemia; curaduría.

\section{Primeiras palavras}

A favor da educação de relações étnico-raciais, pensamos formas de ocupar diferentes espaços com a circulação de palavras e a criação de gestos, imagens e narrativas que viabilizem existência e reexistência de afro-brasileiros protagonistas. No enfrentamento à violência racista, sobretudo no tempo pandêmico, ocupar o espaço virtual é ação necessária, e possível, para gerar um movimento contrário à ocupação enquanto conquista e domínio. Diante da nossa história de origem colonizadora, esses termos precisam ser superados: ocupar páginas virtuais com arte e sensibilidade, a favor da diversidade, pode ser um caminho de educação antirracista. 
Neste texto, as discussões propostas partem da ação "Fiar com o FIAR v na quarentena", configurada como uma ocupação virtual realizada entre maio e setembro de 2020, e das atividades de pesquisa do FIAR - Círculo de Estudo e Pesquisa de Formação Professores, Infância e Arte. Nas impossibilidades de contato físico e encontros presenciais impostas pela pandemia da COVID-19 e, além disso, considerando a necessidade de criar espaços narrativos de partilhas autobiográficas que convidassem e acolhessem dores e delícias, ânimos e desânimos, esperanças e desesperanças. Modos de ser e estar inventados, que atravessam a trágica situação de um tempo em suspensão, durante uma crise sanitária mundial. Dessa forma, buscaram-se alternativas pelos espaços virtuais, com o intuito de suscitar o contato e dialogar com professores e outros interlocutores na página do grupo no Facebook ${ }^{v i}$, na qual foram criadas publicações diárias em diálogo com a arte e com os referenciais utilizados pelo grupo de pesquisa, como convites para sentir, pensar e fazer.

Dentre as propostas encaminhadas, que versavam sobre Museus, Educação e Arte, Literatura, Sons e Canções, dedicamo-nos, também, a abrir janelas virtuais com elementos artísticos e culturais que possam criar possibilidades de formação e ampliação de repertórios no enfrentamento ao racismo, na direção de pedagogias vitais. É sobre essas janelas que trataremos neste artigo. Baseada na construção dialógica e coletiva do grupo de pesquisa, a série de publicações, denominadas "FIAR com... propostas de Educação Antirracista", foi tecida pela curadoria e comunicação discutidas no subgrupo composto por três fiandeiraspesquisadoras, as quais são professoras da educação básica e realizam estudos de mestrado e doutorado em Educação.

Ao longo do texto, trazemos a perspectiva apontada pelo grupo como educação antirracista com o desenvolvimento das publicações elaboradas a partir da curadoria educativa e dados produzidos na interlocução com o público que interagiu com as referidas publicações no Facebook. Consideramos que a curadoria de conteúdo e forma pode inspirar outras estratégias interativas para ressignificar afetos individuais e coletivos, tão importantes no caminho de conscientização e engajamento contra o racismo.

\section{O que chamamos de educação antirracista?}

Nossas propostas de educação antirracista para a ocupação do espaço virtual foram organizadas considerando as contribuições de Almeida (2018), Cabral (1974), Freire (2001) e 


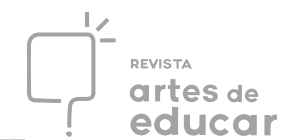

Gomes (2012), autores que contribuem para a luta por uma sociedade implicada em valores democráticos. Empenhamo-nos em produzir narrativas que viabilizassem trajetórias, acontecimentos e espaços que destacam positivamente a negritude. Um desafio imenso diante de um curto post provocativo na rede social, com a intenção de inspirar, pela arte e suas linguagens, ações educativas de combate ao racismo e às discriminações.

Na realidade social observada com toda violência e discriminação racista, classista, sexista e transfóbica parece difícil não ser tomado por rebeldia, qualidade acentuada durante a pandemia, a qual nos impôs a quarentena como cuidado, mas que, em contrapartida, revelou a inexistência de políticas de Estado, a vulnerabilidade social e o descaso com as milhares de mortes. A pandemia mostrou que as agendas políticas neoliberais ampliam as vulnerabilidades das populações historicamente discriminadas (SANTOS, M. et al, 2020), entre as quais a população negra é a mais atingida e exposta ao risco de óbito. Ademais, o contexto revela o racismo como fundamento estruturador das relações sociais no Brasil (ALMEIDA, 2018).

Por educação entendemos um processo de conhecimento que envolve a formação política, manifestação ética e a procura da boniteza (FREIRE, 2001). Defendida por Paulo Freire em Pedagogia da Esperança, a educação assim concebida é a ação imprescindível na humanização do mundo e das relações sociais. Compreende a curiosidade e necessidade humanas em aprender mais e ampliar saberes e possibilidades de atuar no mundo. Considera a esperança de uma sociedade melhor e mais justa, alicerçada na boa convivência, na defesa dos direitos e na participação social de todos. A apreciação da vida, em busca da beleza, na qual encontramo-nos na integralidade de ser, é também pressuposto.

Ao pensarmos e criarmos as propostas para as publicações, lançamos o olhar para as aprendizagens que acontecem ao longo da vida, considerando a intensa relação vida-casa experimentada nos últimos meses. Em sua pedagogia da revolução, Amílcar Cabral inspirounos com a ideia de aprender sempre, na qual está a noção de aprender junto do povo, aprender nos livros e nas experiências dos outros. Cabral defende uma educação emancipadora ao longo da vida e faz, assim, uma aposta para o enfrentamento dos desafios da vida política, cultural, econômica, social e profissional. Ensina que atentar aos arredores pode nos levar a aprender a resistir (CABRAL, 1974).

As definições de racismo são muitas. De acordo com o professor Kabengele Munanga (2004), o racismo é uma prática advinda da crença na existência de raças naturalmente hierarquizadas pela relação intrínseca entre o físico e o moral, o físico e o intelecto, o físico e o cultural. Em suma, estabelece o branco como norma, como superior. Os demais são 


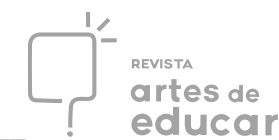

submetidos a determinadas condutas, como o silenciamento, a passividade e a aceitação de inferioridade.

Por racismo entendemos uma violência direta, direcionada à população negra e outras minorias (que são maioria) que possuem raízes estruturais na sociedade (ALMEIDA, 2018). Está presente nas práticas cotidianas, nos discursos, nas instituições, nas relações interpessoais, ocasionando, por exemplo, a falta de respeito, o medo, a desconfiança, a desumanização e a inferiorização de corpos negros. Faz perpetuar desigualdades políticas, sociais e culturais, as quais estimulam diversas injustiças, que ocasionam dores psíquicas e físicas na população discriminada.

Existe, inclusive, uma ideologia racial presente no cotidiano escolar, denunciada pela pesquisadora Nilma Lino Gomes desde a década de 1990. A pesquisadora diz que na escola, enquanto espaço sociocultural, convivemos com os conflitos e as contradições da sociedade, onde o racismo e a discriminação racial e de gênero se fazem presentes:

[...] em frases aparentemente inocentes e tão presentes no imaginário e nas práticas educativas da nossa escola, como por exemplo: "Esta aluna é negra, mas é tão inteligente!" "Eu pensava que a professora do meu filho fosse assim... mais clarinha!" "A professora usa caneta preta porque é preta" (GOMES, 1996, p. 69).

Ser antirracista, para nós, significa resistir e conscientizar-se política e historicamente sobre a diversidade e a desigualdade constitutivas da sociedade brasileira. Revisitar o pensamento de Paulo Freire e Amílcar Cabral ajudam-nos a pensar e construir uma educação popular e emancipadora e, além disso, a recriar atitudes cotidianas, educando-se para as relações étnico-raciais. Engajar-se na luta contra a discriminação racial e as sutis práticas racistas impregnadas nas palavras, nos comportamentos, nos gestos especialmente na escola, é também dispor-se a (re)aprender com os movimentos sociais sobre história, cultura e afirmação da identidade negra. Repensar a formação de professores, ampliar repertórios e compartilhar protagonistas negros e negras no âmbito artístico-cultural foi a direção seguida, resistindo pela ocupação virtual.

\section{No fiar das propostas: curadoria educativa e narrativas (auto)biográficas}

Vivemos em um mundo povoado por imagens, que são captadas por nosso olhar/ corpo 
sensível. As imagens que nos tocam, nos incomodam ou nos causam certo fascínio e admiração provocam em nosso corpo sensações e atualizam e ampliam nosso repertório construído ao longo dos anos em nossa vida escolar, familiar ou social. Mas quantas dessas imagens são feitas por artistas negros? Quais delas trazem à reflexão a educação antirracista? Nessas imagens, como as pessoas negras são representadas?

A relação entre sujeito e objeto é abordada pela arte contemporânea cujo foco é a experiência estética que ocorre na relação entre eles, a qual poderá provocar a construção de uma consciência através da potencialidade da arte. Sob a perspectiva decolonial, entende-se que a arte pode contribuir para interpretar e questionar as narrativas de exclusão e marginalização e pode atuar como sistema de representação que questiona criticamente a realidade (ACHINTE, 2014). Nessa perspectiva, outras possibilidades de pensamentos e modos de vida, de maneiras diferentes de fazer, sentir, atuar e pensar no tempo atual ganham terreno.

Nas publicações que aqui fazemos referência, escolhemos artistas contemporâneos para o diálogo, principalmente pela diversidade e pluralidade de materiais, linguagens e dimensões estéticas colocadas em discussão em seus trabalhos. Considerando o entrelaçamento entre Arte, Formação de Professores e Infância, linhas que se apresentam nas tramas do nosso grupo de pesquisa, fizemos a aposta em reunir Educação e Arte para compor narrativas antirracistas. Assim, pensamos, semanalmente, a relação entre conteúdo e forma a partir de imagens e informações acerca de um tema ou questão, delimitados por uma curadoria educativa.

O conceito de curadoria educativa advém do entendimento que o professor tem o mesmo papel do curador de exposições museológicas, quando seleciona temas e imagens que serão apresentados aos seus alunos. Toda a escolha desses sujeitos se faz a partir de seu repertório visual, estético e cultural, assim como revela uma intenção. Luiz Guilherme Vergara (1996) afirma que o objetivo da curadoria educativa é o de "explorar a potência da arte como veículo de ação cultural" (VERGARA, 1996, p. 4). No mesmo texto, o autor traz-nos a seguinte reflexão:

A Ação Cultural da Arte implica em dinamização da relação arte/indivíduo/ sociedade - isto é, formação de consciência e olhar. [...] ao se propor a exibição de arte como ação cultural - se tem como objetivo criar uma perspectiva de alcance para a arte ampliada como multiplicadora e catalisadora dentro de um processo de conscientização e identificação cultural (VERGARA, 1996, p. 4, grifos do autor).

A construção do olhar e a ampliação de repertórios realizados a partir da experiência estética são "sem dúvida um veículo de materialização da consciência - Estar e Ser no Mundo 
- se revelando pelo tempo e experiência" (VERGARA, 1996, p. 5). Os artistas como sujeitos que pertencem a um tempo, espaço e sociedade materializam em sua arte todas as questões que os constituem como sujeitos sociais que são. E é no contato com sua arte que nós, como público, também sujeitos sociais pertencentes de um tempo e espaço, poderemos ter uma experiência estética, o produto de sua arte pode vir a nos provocar deslocamentos. É como nos diz Paulo Freire: "o homem é um ser de relações e não só de contatos, não apenas está no mundo, mas com o mundo" (1991, p. 39).

Para esclarecer um pouco mais a questão da curadoria educativa, traçamos pontes com a conversa produzida por Gisa Picosque e Mirian Celeste Martins (2003) para o material educativo da Quarta Bienal do Mercosul em Porto Alegre/2003. As autoras afirmam:

Como em toda curadoria, a escolha das imagens faz trabalhar o olhar, um olhar escavador de sentidos. Olhar mais profundo e ao mesmo tempo sem pressa, ultrapassando o reconhecimento, o fim utilitário das imagens, e que se torna um leitor de signos. Nesse movimento do olhar, segundo o filósofo francês Georges Didi-Huberman ${ }^{7}$, não só olhamos a obra como ela também nos olha. Atento aos sentidos das imagens, tal qual um arqueólogo que escava à procura do desconhecido, o professor-pesquisador é um leitor de imagens que elege aquelas que vão adentrar na sala de aula para o deleite e investigação dos alunos.

Nessa tarefa de leitura, as sandálias de professor-pesquisador imantam imagens para compor uma seleção, uma combinação de imagens. Seleção é dizer sim e não, sempre é ênfase e exclusão. Combinação é recorte. Todo recorte é comprometido com um ponto de vista que se elege, exercendo a força de uma ideia, de um conteúdo que é desejo explorar ou de uma temática possível de desencadear um trabalho junto aos alunos.

Selecionar e combinar são, então, uma interpretação do professorpesquisador. Não uma interpretação que cria a armadilha de responder questões, mas a interpretação que vai propor aos alunos um processo instigante de novas e futuras escavações de sentido. Interpretação entendida como um encontro 'entre um dos infinitos aspectos da forma e um dos infinitos pontos de vista da pessoa' ${ }^{8}$ Pontos de vista que, se socializados num grupo, proliferam em múltiplos sentidos. (MARTINS e PICOSQUE, 2003, p. 8)

Ao propor uma prática educativa antirracista é essencial ter em vista quais imagens serão apresentadas no convite ao tema; que tipo de mensagens tais imagens vão passar ao espectador/ sujeito que estará em contato com a obra de arte. Se queremos desconstruir estruturas racistas, não podemos seguir apresentando imagens que colocam os negros em determinadas situações de inferioridade. O desafio é pensar fora da caixa hegemônica da arte de pessoas brancas, vindas da Europa e fixadas como padrão de belo e respeitável, seguindo em busca de artistas que representem através da sua arte questões que nos provocam 
deslocamentos, que puxam fios que nos levem por outros caminhos.

No movimento inicial, encontramos uma fotografia da obra "A parede da memória" (1994-2015) de Rosana Paulino. Na imagem, percebe-se uma parede com 1.500 patuás, pequenas peças usadas como amuletos de proteção por religiões de matriz africana. A obra materializa uma investigação da própria identidade da artista a partir de seus ancestrais. É uma produção de uma artista mulher negra do nosso tempo. Concordamos, então, que deveria inaugurar a janela virtual que se abria ao nosso movimento de pesquisa.

Aquela experiência visual, a partir da arte de Rosana Paulino, gerou desejo de conversa. Tocou nossos sentidos. Trouxe lembranças e narrativas de nossas identificações com a negritude. E, também, a rememoração de episódios de racismo. O espaço de diálogo aberto para a curadoria das publicações nos levou a estudos e debates profundos, como o lugar dos brancos na luta antirracista. Nossos estudos estavam baseados em abordagens (auto)biográficas, nas quais, e pelas quais, a narrativa é tempo e espaço para afirmar a experiência.

Para Benjamin as narrativas contam os fios de nossa história (1993). Assim, a verdadeira narrativa não se esgota, conserva suas forças mesmo depois de muito tempo e ainda é capaz de desdobramentos.

A narrativa, que durante tanto tempo floresceu num meio artesão, é ela própria num certo sentido, uma forma artesanal de comunicação. Ela não está interessada em transmitir o puro assim da coisa narrada, como uma informação ou um relatório. Ela mergulha a coisa na vida do narrador para em seguida retirá-la dele. Assim, imprime-se na narrativa a marca do narrador, como a mão do oleiro na argila do vaso. (BENJAMIN, 1993, p. 221)

$\mathrm{Na}$ relação com o presente, a rememoração nos trouxe um novo olhar para as situações e imagens do passado, entendidas como uma experiência relacionada à questão racial. Foi pelo movimento em direção aos sujeitos e às nossas próprias histórias que encontramos, nos estudos acerca das histórias de vida, fundamentos para sustentar este trabalho. É importante considerar que, além de ser um instrumento de investigação, as abordagens (auto)biográficas também são um instrumento de formação (NÓVOA; FINGER, 2014). Dessa forma, no desenhar das propostas, produzimos conhecimentos e ampliamos nossa formação sensível e epistemológica.

As propostas de educação antirracista que fomos compondo nasceram pelo diálogo com o outro e com a vida, pelos fios da arte e da educação, pelo movimento de curadoria educativa - pesquisa, leitura de imagens, seleção, combinação, recorte e interpretação -, pelo debate sobre cada publicação, pelas narrativas das histórias de vida e pelos comentários dos interlocutores. Dessa forma, deu-se visibilidade ao protagonismo negro, seus espaços, acontecimentos 


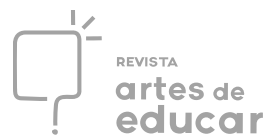

pessoais e profissionais que, nos diálogos/provocações tramados, afetam pessoas negras e não negras. A ocupação virtual foi assim, enegrecendo a rede social com provocações estéticas.

\section{Na ocupação virtual: propostas, interação, alcance e envolvimento do público}

$\mathrm{Na}$ ação "FIAR com... FIAR na quarentena", a cada dia publicamos uma proposta-fio que alinhava convites à reflexão, a sentir, a pensar e a fazer. Segunda-feira: FIAR com... museus; Terça-feira: FIAR com... Educação e Arte; Quarta-feira: FIAR com... literatura; Quinta-feira: FIAR com... sons e canções; Sexta-feira: FIAR com... propostas de educação antirracistas. Essas propostas possibilitam espaços de narrativas, a ampliação do repertório cultural e a construção de conhecimento e de encontros com a arte e artistas.

O "Fiar com... Propostas de Educação Antirracista" estreou durante o isolamento social, na primeira sexta-feira de maio/2020. Para a leitura dos dados neste texto, consideramos um total de quatorze publicações. Com a ação ainda em desenvolvimento, delimitamos o período entre 03 de julho e 21 de agosto de 2020. No conteúdo publicado, articulamos texto, imagem e indicações de páginas virtuais destinadas ao público em geral. FIAR com propostas de educação antirracista é uma das ações mais acessadas na página do Facebook do grupo.

A proposta número 1 trouxe como inspiração a memória e a arte de Rosana Paulino ${ }^{\text {vii }}$. A partir desse fio, outras histórias foram puxadas. Na sequência das publicações: 2) A pergunta: “Professor@, como você enfrenta o racismo?" a partir da narrativa de uma professora e a história da bailarina Ingrid Silva ${ }^{\text {viii }}$; 3) O questionamento sobre um repertório visual antirracista, a partir da arte contemporânea, alinhado à performance "Bombril" de Priscila Rezende ${ }^{\mathrm{ix}}$; 4) "Uma poética antirracista" a partir de "Ainda assim, eu me levanto" da poetisa norte-americana Maya Angeloux; 5) A questão: “O que você já fez hoje na luta antirracista?” acompanhada do alerta das obras de No Martins ${ }^{\mathrm{xi}}$; 6) Problematizando a ideia de que arte é para gente rica e branca, a produção do jovem artista paulistano Robinho Silva ${ }^{x i i}$; 7) Considerando nossa ancestralidade, em busca de fragmentos de família, apresentamos a artista-artesã Sonia Gomes $^{\text {xiii }}$; 8) A palestra-performance de Grada Kilomba ${ }^{\text {xiv }}$; 9) Insubmissas trajetórias de mulheres negras para inspirar propostas de educação antirracista, destacando Luiza Mahin ${ }^{\mathrm{xv}} \mathrm{e}$ outras onze mulheres negras; 10) O cabelo, que não passa despercebido nas relações sociais, abordado na pesquisa de Luane Bento ${ }^{x v i}$; 11) Lélia Gonzalez ${ }^{x v i i}$, um símbolo de resistência e da luta pelos direitos de indígenas, negros e mulheres nos anos 1970/1980; 12) A comunidade 
da Mangueira e os parangolés de Hélio Oiticica ${ }^{\text {xviii }}$; 13) São muitas Carolinas: escritora, intelectual, cantora, compositora, artista circense e atriz Carolina de Jesus ${ }^{\mathrm{xix}}$; 14) A Anástacia livre na obra de Yhuri $\mathrm{Cruz}^{\mathrm{xx}}$; 15) A representatividade que importa através de Dona Ivone $\operatorname{Lara}^{\mathrm{xxi}}$.

Na imagem, apresentamos as 15 publicações como uma foto-ensaio elaborada a partir de imagens utilizadas na ocupação virtual, como uma espécie de criação e invenção digital que narram visualmente a experiência vivida/provocada (SILVA, 2017).

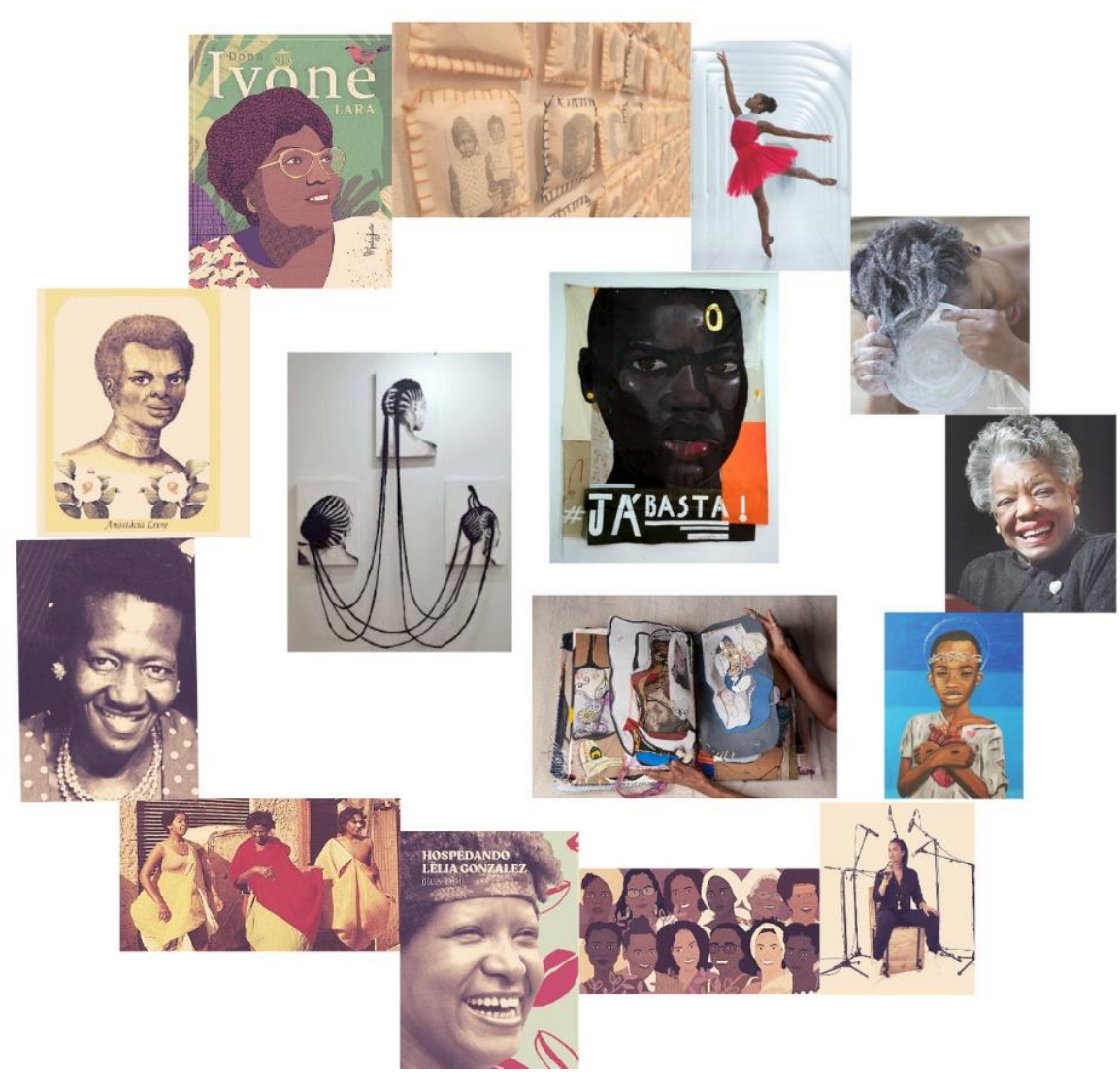

Fonte: Foto-ensaio composto por 15 imagens compartilhadas na página do Facebook em diálogo com a publicação FIAR com propostas de educação antirracista.

Considerando as informações fornecidas pela rede social a partir dos dados de alcance, que é o número de visualizações e de envolvimento caracterizado pelas reações e compartilhamentos, destacam-se três publicações. Acreditamos que essas propostas podem nos ajudar a criar outras estratégias na direção de uma educação antirracista, considerando formação e pesquisa na virtualidade que nos impõe esse momento, em espaços de vida com arte, beleza e diversidade.

No "FIAR com... propostas de educação antirracista" número 09 (nove), publicada em 


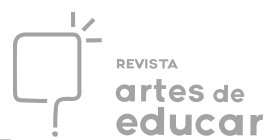

03 de julho/2020, apresentamos a cultura de trançar cabelos nos grupos afro-brasileiros, objeto de estudo da professora Luane Bento. Para a pesquisadora, “o cabelo não passa despercebido nas relações sociais, a ausência ou presença do cabelo representa algum sentido e tem suas relevâncias" (SANTOS, 2013, p. 26). Em seu estudo, a prática de trançar cabelos é entendida como uma memória mantida na cultura negra brasileira. A experiência de mulheres negras trançadeiras e seus fazeres e saberes são invisibilizadas, por exemplo, como forma de conhecimento matemático na sociedade brasileira, segundo a autora.

A publicação com maior envolvimento trouxe como pergunta: De que modo você utiliza seu cabelo? Quais sentidos imperam? Na imagem, a obra "Formation" criada pela artista Lebohang Lang Motaung ${ }^{x x i i}$ e representada por tranças que se interligam. Destaca-se, ainda, uma proposta-interação: Compartilhe uma foto e conte-nos a história do seu cabelo. Nos comentários, os interlocutores compartilharam suas experiências. Aqui destacamos duas:

Gostar do cabelo em muitas circunstâncias é um processo. Na adolescência meu apelido era em função do impacto que meu cabelo causava... por um tempo isso me incomodou muito. Hoje tento mantê-lo o mais prático possível. O tempo passa e a gente vai reavaliando...hoje vejo que manter o meu cabelo ao natural é uma questão de identidade. Entendo também que é uma forma de afirmação. Sou feliz liberta das químicas. Mas adoro um cabelo colorido kkk. (X. M.)

Quais sentidos imperam? O de Liberdade, aceitação, de autoestima. Precisei recomeçar. Foram quase 30 anos, negando a minha essência. Hoje me sinto muito mais feliz, mas ainda em constantes processos. (H.N.)

A segunda publicação com maior envolvimento provocou a discussão acerca da ancestralidade e dos fragmentos de família. Essa foi a sexta postagem publicada em 19 de março/2020 sobre propostas de educação antirracista e buscou estabelecer o diálogo da arte com as histórias de artistas negros. Nossa inspiração artística ficou por conta da obra Mãos de Ouro, que acompanhou o texto da publicação nas redes. Criada em 2008 por Sônia Gomes, apresenta em formato de livro uma composição feita com grafite, caneta, costura, amarrações, tecidos e rendas variadas sobre papel. Marca da artista-artesã mineira, que tece sua obra por meio da costura, torções, confluências e união de arame, rendas, tecidos, papel, linhas, papelão e bordados.

Nascida em Caetanópolis, MG, de mãe negra e pai branco, Sonia Gomes é uma fusão também de muitas lembranças. Sônia traz a influência forte da avó, parteira, benzedeira e useira de rodilhas na cabeça. Da família branca, herdou a ruminação dos guardados, das fotos, dos retalhos de tecidos vindos da fábrica, dos afetos fragmentados. (PRÊMIO PIPA, 2020) 
Indagamos: considerando sua ancestralidade, quais fragmentos de família você guarda?

Os fragmentos de família que guardo são linha e agulha. Fiquei encantada pelo trabalho da Sonia Gomes. Seu trabalho lembrou as produções artísticas da minha avó. Ela gostava de criar escultura, fazia com garrafas ou galhos secos. E tinha tb esse lado benzedeira, com Guiné e arruda num defumador para espantar maus espíritos as sextas feiras. (G. S.)

Dos fragmentos que guardo, muitos são relacionados a música. Mas, agora sinto essa ancestralidade no cuidado com as plantinhas, aprendendo a amar esse contato mais direto e relacional com o verde. (L. V.)

Na sequência, a publicação que traz o artista paulistano No Martins mobilizou os participantes. Foi à rede social no dia 05 de junho/2020, trazendo um recado: aos que foram, aos que aqui estão e aos que virão: a luta antirracista é ação! Na semana em que o racismo entrava em pauta, com mais força, nas mídias sociais, devido à morte de George Perry Floyd Jr - homem negro afro-americano assassinado por agentes da polícia, em Minneapolis, nos Estados Unidos. Quando, no Brasil, noticiava-se a morte de João Pedro, um menino de 14 anos que fora assassinado dentro de casa, no complexo do Salgueiro em São Gonçalo, região metropolitana do Rio de Janeiro. Onde, também, circulavam as notícias de Miguel, menino de apenas 05 anos, que morreu enquanto estava aos cuidados da patroa de sua mãe em área nobre do Recife, Pernambuco.

Em uma semana de tamanha violência, buscava-se por justiça, esperança e atitudes antirracistas. Dessa forma, as pinturas do artista No Martins ativaram dor e denúncia. Sua produção artística transita pelas linguagens da pintura, performance e experimentações com objetos como sinais de alerta. Dá-se a partir de pesquisas sobre as relações interpessoais no cotidiano. Aborda o convívio e os problemas enfrentados por negros e negras no cotidiano urbano, põe em pauta o racismo, a violência policial e o genocídio da população negra brasileira. A inscrição \#Jábasta faz parte de uma série do artista e inspira-se nas grandes campanhas nas redes sociais. Escolhemos uma das obras para a veiculação da publicação. Produzida em 2019, em acrílica sobre tecidos diversos, traz a imagem de um homem negro com olhar profundo e abaixo a escrita \#Jabasta.

Da proposta-interação: O que você já fez hoje na luta antirracista? Trazemos aqui duas respostas de pessoas que interagiram conosco nesta publicação

Assistimos filmes com protagonismo negro, revi a quantidade de livros antirracistas de meu filho. Enviei um zap para a coordenadora pedagógica da escola do meu filho com sugestões de livros infanto juvenis de boa qualidade. 
Tenho conversado com meu filho sobre o que está acontecendo com a humanidade. (X. M.)

Conversando muito sobre o lugar de fala, branquitude e práticas antirracistas com amigas brancas.

Em contato diário com as educadoras de educação infantil, trago sugestões para pensarmos em propostas que valorizem a cultura negra e indígena.

Buscando leituras, vídeos, de pessoas engajadas com a luta, que me façam deslocar o olhar e ampliem minhas percepções.

Em Casa... com o filho e esposo, o diálogo que já existia, intensificou. Ainda é Muuuito pouco. Então peço, vamos juntos. Assim chegaremos mais longe. (H. N.)

Infelizmente, o racismo continua em pauta nas redes e nas notícias. A irracionalidade continua a exterminar a vida de pessoas negras, principalmente durante a crise da COVID-19. Os dados de alcance e envolvimento mostram que ocupamos o espaço da rede social, e o tempo de algumas pessoas, com conteúdo político e histórico sobre a diversidade, com a presença negra de artistas e das artes, com beleza e poesia como forma de resistência. Ainda assim, sabemos que é preciso de muito mais.

\section{Da fiação de propostas à trama antirracista}

A arte trouxe para nós a oportunidade de cuidado e curadoria da forma e do conteúdo, provocadora de diálogos na pandemia; ajudou-nos a ressignificar afetos individuais e coletivos, tão importantes no caminho da consciência do racismo; permitiu-nos perceber o outro pelas lentes da sensibilidade; contribuiu no reconhecimento da negritude que constitui a população brasileira; e, ainda, trouxe possibilidades de identificação enquanto negros na declaração política e/ou nos modos de ver e viver.

A partir das publicações do FIAR e seu alcance, vimos o corpo negro no centro do interesse. O cabelo, principal alvo das atitudes discriminatórias, foi abordado em suas múltiplas formas, sentidos e saberes, desde a cultura ancestral até os nossos dias. A opção pela arte contemporânea nos brindou com a interação da artista mineira na página. Essa tem sido uma das bonitezas de trabalhar com arte contemporânea, uma vez que muitos artistas são ativos em suas redes sociais e acabam interagindo com o público.

Na semana em que o mundo explodiu com as manifestações vidas negras importam, cartazes e postagens ocuparam as principais redes sociais. Naquele momento, no Brasil, a morte de João Pedro e Miguel, duas crianças negras que perderam suas vidas de forma abrupta. 
Fica mais difícil respirar depois dessas notícias. Nós, que já estamos em uma ocupação virtual antirracista, endossamos o coro: parem de nos matar!

A violência, a discriminação e o racismo geram revolta. Contudo, que sejam capazes, também, de gerar envolvimento e engajamento na luta. Na elaboração do FIAR com propostas de educação antirracista, colocamo-nos ao lado daqueles e daquelas que militam contra o ódio e a opressão. Seguimos na busca por justiça, fiando e (con)fiando atitudes éticas e estéticas, na direção da educação antirracista pautada na vida, na arte e na boniteza.

\section{REFERENCIAS}

Almeida, S.L. O que é racismo estrutural? Ed. Belo Horizonte: Letramento, 2018. v. 1.

ACHINTE, Adolfo. Arte, docencia e investigación. In: BORSANI, María Eugenia. QUINTERO, Pablo. (orgs.). Los desafíos decoloniales de nuestros días: pensar en colectivo. Neuquén: Educo Editorial de la Universidad Nacional del Comahue, 2014.

BENJAMIN, Walter. Obras escolhidas: magia e técnica, arte e política. São Paulo: Brasiliense, 1993.

CABRAL, Amílcar. PAIGC: Unida e Luta. Lisboa: Nova Aurora, 1974.

FREIRE, Paulo. A educação como prática para a liberdade. Rio de Janeiro: Paz e Terra, 1991.

Política e educação: ensaios. 5. Ed. - São Paulo, Cortez, 2001.

GOMES, Nilma Lino. Educação, raça e gênero: relações imersas na alteridade. Cadernos Pagu: raça e gênero, Campinas: Unicamp, v. 6-7, p. 67-82, 1996.

HILLMAN, James. O pensamento do coração e a alma do mundo. Campinas, SP: Verus, 2010.

MARTINS, Mirian Celeste (coord.). Curadoria educativa: inventando conversas. Reflexão e Ação - Revista do Departamento de Educação/UNISC - Universidade de Santa Cruz do Sul, vol. 14, n.1, jan/jun 2006, p.9-27.

. e PICOSQUE, Gisa. Inventário dos Achados - O olhar do professor-escavador de sentidos - 4 a. Bienal. Porto Alegre: Fundação Bienal de Artes Visuais do Mercosul, 2003.

MUNANGA, Kabengele. Uma abordagem conceitual das noções de raça, racismo, identidade e etnia. In: Programa de educação sobre o negro na sociedade brasileira [S.1: s.n.], 2004.

NÓVOA, A; FINGER, M. (Org.). O método (auto)biográfico e a formação. Natal, RN: EDUFRN; 2 ed. São Paulo: Paulus, 2014. 
Prêmio PIPA. Sonia Gomes. disponível em https://www.premiopipa.com/pag/sonia-gomes/ Acesso em 16 set 2020.

SANTOS, Márcia; NERY, Joilda; GOES, Emanuelle; SILVA, Alexandre da; SANTOS, Andreia; BATISTA, Luis Eduardo; ARAÚJO, Edna. População negra e Covid-19: reflexões sobre racismo e saúde. Estud. av. vol.34 no.99 São Paulo May/Aug. 2020 Epub July 10, 2020.

SANTOS, Luane. Para além da estética: uma abordagem etnomatemática para a cultura de trançar cabelos nos grupos afro-brasileiros. 2013. Dissertação (Mestrado apresentada ao Programa de Pós-Graduação em Relações Etnicorraciais) - Centro Federal de Educação Tecnológica Celso Suckow da Fonseca, CEFET/RJ.2013.

SILVA, Greice D. de B. De dentro pra fora, de fora pra dentro: itinerários de formação estética de professoras da educação infantil. 2017. Dissertação (Mestrado em Educação) Universidade Federal Fluminense. Niterói, 2017

VERGARA, Luiz Guilherme. Curadoria Educativa: Percepção Imaginativa/ Consciência do Olhar. Texto apresentado no Encontro da ANPAP- São Paulo 1996.

\footnotetext{
i Doutoranda pelo Programa de Pós-Graduação em Educação da Universidade Federal Fluminense. Professora EBTT. COLUNI UFF. Pesquisadora no FIAR/FEUFF. https://orcid.org/0000-0002-8655-8034. E-mail: greiceduarte@id.uff.br

ii Arte Educadora da rede Estadual de Educação do Rio de Janeiro e do município de Itaboraí. Com especialização em Arte e Cultura pela UCAM. Mestranda em educação da Universidade Federal Fluminense. Pesquisadora no FIAR/FEUFF. https://orcid.org/0000-0001-9478-9599. E-mail: mellograzi@ hotmail.com

iii Professora da Educação Infantil da Rede Municipal de São Paulo. Com especialização em direito educacional. Pesquisadora no FIAR/FEUFF. https://orcid.org/0000-0002-7573-467X.
}

iv Inscrito no diretório do CNPq como FIAR - Círculo de Estudo e Pesquisa Formação de professores, Infância e Arte. http://fiar.sites.uff.br/mariahelenadantas@globo.com.

v Conheça mais sobre o FIAR em http://fiar.sites.uff.br/

vi Veja a página do FIAR na rede social https://www.facebook.com/fiar.pesquisa

vii Sobre Rosana Paulino, veja mais em https://enciclopedia.itaucultural.org.br/pessoa216153/rosana-paulino viii Sobre Ingrid Silva, conheça https://brasil.elpais.com/brasil/2019/11/04/cultura/1572860654_696874.html ix Sobre Priscila Rezende, veja mais em http://priscilarezendeart.com/

x Leia o poema de Maya Angelou na íntegra https://www.geledes.org.br/maya-angelou-ainda-assim-eu-melevanto/

xi Sobre No Martins, veja em https://arteref.com/dossie/no-martins-aos-que-se-foram-aos-que-aqui-estao-e-aosque-virao/

xii Sobre Robinho Santana, veja mais em https://www.youtube.com/watch?v=inwxNSvOpno

xiii Sobre Sonia Gomes, veja mais em https://www.ufrgs.br/arteversa/?p=1471

xiv Sobre Grada kilomba, veja mais em

https://brasil.elpais.com/brasil/2019/08/19/cultura/1566230138_634355.html

xv Sobre Luísa Mahin, veja mais em http://antigo.acordacultura.org.br/herois/heroi/luizamahin

xvi Sobre as pesquisas de Luane Bento, veja mais em

https://scholar.google.com.br/citations?user=QSVNe80AAAAJ\&hl=pt-BR\#d=gs md cita-

$\mathrm{d} \& \mathrm{u}=\% 2 \mathrm{Fcitations} \% 3 \mathrm{Fview}$ op\%3Dview citation\%26hl\%3Dpt-

BR\%26user\%3DQSVNe80AAAAJ\%26citation_for_view\%3DQSVNe80AAAAJ\%3AUeHWp8X0CEIC\%26tzo $\underline{\mathrm{m} \% 3 \mathrm{D} 180}$

Revista Interinstitucional Artes de Educar. Rio de Janeiro, V. 7, N. 1 - pág. 571-585 janeiroabril de 2021: "Pedagogias Vitais: Corpo, Desejo e Educação" DOI: 10.12957/riae.2021.55365 
xvii Sobre Lélia Gonzalez, veja mais em https://bityli.com/OcpYQ

xviii Sobre os parangolés de Hélio Oiticica, veja mais em http://artcontexto.com.br/artigo-edicao04wesley_stutz.html

xix Sobre Carolina de Jesus, veja mais em https://www.youtube.com/watch?v=7laZrkEafYI

xx Sobre Yhuri Cruz, veja mais em https://yhuricruz.com/bio/

xxi Sobre Dona Ivone Lara, veja mais em https://issuu.com/itaucultural/docs/jornal_sonhomeu_donaivonelara

xxii Saiba mais sobre Lebohang Lang Motaung em https://www.instagram.com/lebohanglang/

Revista Interinstitucional Artes de Educar. Rio de Janeiro, V. 7, N. 1 - pág. 571-585 janeiro-

abril de 2021: "Pedagogias Vitais: Corpo, Desejo e Educação" DOI: 10.12957/riae.2021.55365 